\title{
KONDISI SOSIAL BUDAYA BERPANTANG MAKANAN DAN PERAWATAN KEHAMILAN PADA SUKU TOLAKI (STUDI KASUS PADA MASYARAKAT PESISIR KOTA KENDARI) TAHUN 2019
}

\author{
Hartati Bahar ${ }^{1}$ Febriana Muchtar ${ }^{2}$ Linda Ayu Rizka Putri ${ }^{3}$ \\ , 12 Fakultas Kesehatan Masyarakat Universitas Halu Oleo ${ }^{3}$ Stikes Karya Kesehatan Kendari \\ 1'hartati.bahar@uho.ac.id ${ }^{2}$ febrianamuchtar@yahoo.com3lindapubhealth09@gmail.com
}

\begin{abstract}
Abstrak
Perawatan kehamilan merupakan salah satu faktor yang perlu diperhatikan untuk mencegah terjadinya komplikasi dan kematian ketika persalinan, disamping itu juga untuk menjaga pertumbuhan dan kesehatan janin. Penelitian ini bertujuan untuk mengetahui dan menganalisis faktor sosial budaya ibu hamil suku tolaki dalam berpantang makan pada masyarakat pesisir Kota Kendari. Penelitian ini menggunakan penelitian kualitatif dengan pendekatan studi kasus. Cara mendapatkan informasi melalui wawancara mendalam dan observasi lapangan. Hasil penelitian menunjukkan terdapat kepercayaan berpantang makanan masih ada hingga saat ini, beberapa jenis makanan yang dipantang oleh suku tolaki di Kota Kendari adalah jenis sayuran nangka, terong, papaya, nenas, dan pisang mentah. Jenis minuman yang dipantang yakni minum susu dan minum air es. Makanan yang manis-manis seperti gula merah juga dipantang termasuk makanan bersantan dan berminyak. Dari jenis hewani dipantang makan ikan masak karena dikhawatirkan akan membuat ASI berbau busuk dan amis. Makanan yang dianjurkan adalah jenis kacang tanah, sayur bening dan ikan panggang. Untuk perilaku perawatan kehamilan ibu hamil dilarang keluar rumah kecuali membawa jimat yang dipercaya bisa melindungi ibu hamil dan bayinya dari roh jahat. Dilarang pula makan didalam kamar dan ketika makan harus memberitaukan ke suami agar ibu tidak memberaki dirinya saat melahirkan. Kesimpulan penelitian ini adalah masih terdapat budaya berpantang makanan selama kehamilan pada suku tolaki juga masih terdapat tata cara perawatan kehamilan pada ibu hamil berupa perilaku berpantangan dan anjuran selama kehamilan.
\end{abstract}

Kata kunci: sosial budaya, suku tolaki

\begin{abstract}
Prenatal care is one of the considerable factors to prevent complication and death during delivery, in addition to maintaining fetal growth and health. This study aimed to understand and analyse sociocultural factors of Tolaki pregnant women in food taboo/abstaining in coastal communities of Kendari. The present study was a qualitative study with a case study approach. Information was collected through in-depth interview and field observation. The results of the study showed that food abstaining still exists. Some types of food that were prohibited by the Tolaki people in Kendari were types of jackfruit, eggplant, papaya, pineapple, and raw banana. Furthermore, types of beverages that were taboo were milk and ice water as well as sweet foods such as brown sugar, coconut milk and oily foods. Of animal types, it is prohibited to eat cooked fish because it is feared that it will make the milk smell foul and fishy. The recommended foods are types of peanuts, boiled vegetables and grilled fish. In term of behaviour, pregnant women are prohibited from leaving the house unless carrying a charm that is believed to protect pregnant women and their babies from evil spirits. It is also forbidden to eat in the bedroom and must inform the husband before eating so that the mother does not excrete to herself during childbirth. The conclusion of this study is that there is still a culture of abstaining from food during pregnancy in the Tolaki tribe and there are still procedures for prenatal in the form of abstinence and suggestions during pregnancy.
\end{abstract}

Key words: socio-culture, Tolaki Tribe 


\section{PENDAHULUAN}

Kemenkes melansir bahwa Tingginya Angka Kematian (AKI) di Indonesia mencapai 305/100.000 kelahiran (Profil Kesehatan Indonesia, 2015) ${ }^{1}$. Tinggimya AKI tersebut mendorong pemerintah untuk melakukan intervensi struktural; salah satunya adalah dengan mencantumkan target penurunan AKI ke dalam Rencana Pembangunan Jangka Menengah Nasional (RPJMN) 2014-2019. Dalam RPJMN 20142019, pemerintah menargetkan penurunan AKI dari 205/100.000 kelahiran m

enjadi 276/100.000 kelahiran hidup. Artinya diharapkan setiap 100.000 kelahiran terdapat 205 Kemarian Ibu. Namun upaya ini belum menunjukkan hasil yang berarti, kematian Ibu melahirkan ini dikarenakan karena komplikasi selama melahirkan yang disebabkan oleh banyak factor salah satunya pendarahan dan anemia.

Anemia pada ibu hamil meningkatkan frekuensi komplikasi pada kehamilan dan persalinan, keguguran, angka prematuritas, Berat Bayi Lahir Rendah (BBLR), kematian neonatal, kematian perinatal hingga risiko kematian maternal. Di samping itu, perdarahan lebih sering dijumpai pada wanita yang anemia dan lebih sering berakibat fatal, sebab wanita yang anemia tidak dapat mentolerir kehilangan darah, ibu hamil yang menderita anemia juga dapat mengalami kegagalan jantung yang dapat mengakibatkan kematian. Sedangkan dampak sosial ekonomi akibat anemia adalah penurunan produktifitas. Apabila ibu hamil dapat melahirkan bayi dengan selamat maka bayi tersebut cenderung memiliki perkembangan kecerdasan lebih rendah bila dibandingkan anak-anak lain yang normal. ${ }^{2}$

Beberapa kondisi keluhan karena anemia inu hamil dianggap hal yang wajar, seorang wanita dianggap sehat dan kehamilannya dianggap sehat, namun demikian dalam banyak kebudayaan kondisi hamil itu dianggap menempatkan wanita dalam kondisi khusus yang bisa pula mendatangkan bahaya bagi dirinya atau bagi bayi dalam kandungannya. Secara umum adalah lazim adanya kepercayaankepercayaan tertentu menyangkut ibu hamil dan anak yang dikandungnya, sehingga bagi ibu hamil dikenakan banyak keharusan atau larangan tertentu yang berlaku secara turun temurun. Kondisi ini secara tidak langsung dapat berhubungan dengan kesehatan kehamilan misalnya pada ibu yang banyak berpantang makan karena factor "Taboo" selama hamil berisiko untuk kekurangan zat gizi tertentu misalnya zat besi.

Dalam memahami suatu masalah perilaku kesehatan harus dilihat dalam hubungannya dengan kebudayaan, organisasi sosial, dan kepribadian individu-individunya ${ }^{3}$. Berdasarkan hal tersebut, pembahasan mengenai kontribusi faktor sosial budaya ibu hamil merupakan faktor menarik untuk dikaji khususnya pada suku tolaki di daerah pesisir Kota Kendari

\section{METODE}

Penelitian ini menggunakan "metode kualitatif" dengan pendekatan studi kasus. Esensi dari penelitian ini adalah mencoba mendapatkan gambaran peran aspek sosial budaya pada pola ibu hamil dalam kepercayaan berpantang terhadap makanan tertentu pada suku tolaki. Triangulasi metode pengumpulan data adalah wawancara mendalam dan observasi terhadap informan sebagai fakta untuk memperkuat analisis.

Penentuan informan dalam penelitian ini dilakukan secara purpossive sampling dengan pertimbangan bahwa informan yang dipilih dianggap dapat memberikan informasi secara mendalam tentang perilaku ibu hamil yang berkaitan dengan pola konsumsi makanan pada suku tolaki

Peneliti melakukan FGD dan wawancara mendalam secara langsung dengan menggunakan panduan yang telah disusun sebelumnya untuk menggali lebih jauh informasi seputar perilaku ibu hamil dalam pola konsumsi makanan makanan tertentu. Hasil diskusi dan wawancara dicatat dan direkam dengan menggunakan tape recorder dan kamera.

\section{HASIL DAN PEMBAHASAN}

Pandangan informan mengenai kehamilan yang berhubungan dengan budaya suku Tolaki dapat digambarkan sebagai berikut:

1. Selama kehamilan tidak boleh makan nangka, popaya, yang gatal-gatal nda boleh

2. Istilah pantangan dan pamali dalam suku tolaki dikenal dengan istilah "Saha"

3. Kehamilan bagi suku tolaki di anggap anugerah dan titipan tuhan termasuk pantangan terhadap makanan tertentu sehingga harus dipatuhi.

4. Pandangan budaya suku tolaki dilarang makan nenas karena sifatnya panas.

5. Tidak boleh makan dalam kamar dan tidak boleh makan tidak memberitahu suami, karena nanti pada saat melahirkan dipercayai akan beraki dirinya sendiri.

6. Saat umur kehamilannya mencapai 6 bulan tidak boleh keluar-keluar karena di takutkan jangan sampai terjadi apa-apa dengan kandungannya. Kalau kandungan masih berusia 3-4 bulan masih bisa keluar rumah dan pada saat kandungan 7 bulan sampai menjelang kelahiran tidak boleh keluar kecuali pakai wuroi ( jimat) supaya tidak ada roh-roh jahat yang mengganggu ibu dan bayinya.

7. Ibu hamil dilarang keluar subuh hari, jikapun harus keluar harus memakai jimat "dariango"

8. Dilarang minum susu atau air es jangan sampai besar dia punya bayi dan susah melahirkan. 
9. Dilarang makan makanan kecut-kecut, akan tetapi yang manis tidak di larang.

10. Upacara adat pada saat hamil menurut pandangan suku tolaki dikenal dengan istilah "pandamangido".

11. Perawatan yang dilakukan pasca melahirkan yaitu ibuinaho (mandi air panas) pake akar panimbul dan diikat perutnya selama 40 hari,

12. Dilarang makan terong dan papaya supaya kandungan tidak melebar.

13. Dilarang jalan, setelah 3 bulan baru dibolehkan karena jangan sampai pendarahan.

14. Dilarang makan makanan yang bersifat gatal seperti terong dan papaya, dan sayur nangka.

15. Dilarang makan gula merah, pisang mentah, makanan yang bersantan, dan juga makanan yang berminyak.

16. Tidak boleh bersisir, nanti setelah selesai 40 hari baru dibolehkan bersisir.

17. Setelah melahirkan dianjurkan makan kacang tanah supaya ada ASI.

18. Dilarang makan ikan masak, karena dipercaya ASI nya akan busuk dan berbau amis.

19. Dianjurkan makan sayur bening dan ikan panggang supaya ASI-nya tidak bau amis.

Kepercayaan-kepercayaan dan pantanganpantangan terhadap beberapa makanan cukup besar pengaruhnya pada kehamilan dan masalah gizi. Pantangan makanan yang sebenamya sangat dibutuhkan oleh wanita hamil tentu akan berdampak negatif terhadap kesehatan ibu dan janin. Menurut Subowo $(2008)^{4}$ penyebab utama dari tingginya angka anemia pada wanita hamil disebabkan karena kurangnya zat gizi yang dibutuhkan untuk pembentukan darah, dan kekurangan zat besi ini bias jadi diakibatkan oleh pantangan-pantangan makanan. Penelitian ini sejalan dengan penelitian yang dilakukan oleh Idrus $(1998)^{5}$ pada suku Bajo yang ada di Kabupaten Kendari, menurut Idrus terdapat pantangan bagi wanita hamil yakni tidak boleh mengambil makanan dari periuk dengan tangannya, tidak boleh makan dengan menggunakan piring yang besar, dan dilarang makan sayur yang terbuat dari daun kelor. Sebahagian besar pantangan-pantangan ini masih diyakini dan dilaksanakan oleh ibu hamil Suku Bajo yang bermukim di daerah pinggiran Kota Kendari.

Pantangan dan tata cara perawatan kehamilan pada ibu hamil dikenali dengan konsep asosiasi dengan bentuk sifat dari bahan makanan yang dipantang merupakan cerminan dari rasa altruisme seorang ibu terhadap anaknya. Altruisme ini tercermin sebagai perhatian terhadap kesejahteraan jabang bayi yang dikandung tanpa memperhatikan diri sendiri, bagi sebahagian orang tua perilaku ini merupakan kewajiban yang harus dilakukan untuk menunjukkan rasa sayang kepada janin (calon anak) yang akan dilahirkan tanpa memperhatikan ganjaran atau keuntungan yang akan didapatkan. ${ }^{6}$

Sumber pengetahuan berpantang makanan ini berlangsung secara turun temurun yang kebanyakan berasal dari mereka yang dianggap panutan, semisal orang tua atau dukun. Apa yang mereka sebut sebagai "pengetahuan" itu sebenarnya bukan merupakan pengetahuan yang dipelajari, namun yang didapatkan dalam daur kehidupan sebagai pewarisan kebudayaan mereka. Khusus di Kecamatan Abeli pemeliharaan kesehatan dan cara-cara penanggulangan masalah kehamilan dilakukan dengan menghindari pantangan-pantangan yang diyakini oleh masyarakat dan didasarkan atas sistem kepercayaan yang berlaku secara turuntemurun sebagai pewarisan kebudayaan.

Pewarisan kebudayaan dapat dilakukan melalui enkulturasi dan sosialisasi. Enkulturasi atau pembudayaan adalah proses mempelajari dan menyesuaikan pikiran dan sikap individu dengan sistem nilai, norma, adat, dan peraturan hidup dalam kebudayaannya. Proses enkulturasi dimulai sejak dini, yaitu masa kanak-kanak, bermula dilingkungan keluarga, teman sepermainan, dan masyarakat luas. ${ }^{7}$

Pantangan atau larangan makan dalam proses kehamilan sangat mempengaruhi kecukupan zat gizi pada ibu hamil, padahal seorang ibu yang sedang hamil seharusnya terpenuhi kecukupan gizinya untuk kepentingan dirinya sendiri dan janin yang sedang dikandungnya. Ibu hamil yang masih secara konsisten berpantang makan banyak ditemukan pada ibu hamil dengan gejala anemia. Selain kebiasaan berpantang makan, ditemukan juga beberapa ibu hamil yang tidak melaksanakan pantangan tersebut. Hal ini dapat dijadikan acuan walaupun masih memerlukan pembuktian lebih lanjut bahwa ibu hamil yang masih konsisten berpantang makan mempunyai kontribusi terhadap kekurangan zat gizi tertentu selama kehamilan. ${ }^{8}$

\section{SIMPULAN DAN SARAN}

Berdasarkan hasil penelitian ini maka dapat disimpulkan bahwa faktor nilai dan norma dalam sosial budaya yang berkaitan dengan kepercayaan tertentu terhadap makanan mempunyai relasi dengan kekurangan zat gizi tertentu pada ibu hamil. Berdasarkan kesimpulan diatas maka disarankan bagi tenaga kesehatan agar memberikan informasi kepada setiap ibu hamil akan bahaya berpantang makan selama kehamilan kemudian diharapkan lebih mendayagunakan sumber-sumber hasil laut sebahai bahan konsumsi makanan bernilai gizi tinggi melalui 
pendidikan kesehatan melalui Posyandu dan melalui media televisi lokal.

\section{DAFTAR PUSTAKA}

1. Kemenkes RI, 2015. Profil Kesehatan Indonesia. Jakarta

2. Darlina dan Hardinsyah, 2003, Faktor Risiko Anemia Pada Ibu Hamil di Kota Bogor, Media Gizi dan Keluarga Vol. 27 No.2.

3. Kalangi Nico S, 2004, Kebudayaan dan Kesehatan; Pengembangan Pelayanan Kesehatan Primer Melalui Pendekatan Sosial Budaya, Megapoin, Jakarta.

4. Subowo Ari, 2008, Kinerja Pembangunan Kesehatan : Tinjauan Disparitas Pelayanan Kesehatan Ibu Dan Anak, "DIALOGUE" Jurnal Ilmu Administrasi dan Kebijakan Publik, Vol. 5, No. 2 : 155-166
5. Idrus Muhammad M, 1998, Pengobatan, Kehamilan, Dan Kelahiran Pada Orang Bajo Di Lasolo, Kabupaten Kendari, dalam Meutia F swasono " Kehamilan, Kelahiran, Perawatan Ibu Dan Bayi Dalam Konteks Budaya". UI-Press: Jakarta.

6. Zaluchu Fotarisman, 2007, Faktor Sosio-psikologi Masyarakat Yang Berhubungan Dengan Anemia Ibu Hamil di Kota Tanjung Balai, Sumatera Utara (11-18), Info Kesehatan Masyarakat Vol. XI, No.1: 11-18, ISSN 1410-6434

7. Herimanto dan Winarno, 2008, Ilmu Sosial dan Budaya Dasar, Bumi Aksara, Jakarta.

8. Astawan Made, 2009, Ensiklopedia Gizi Pangan Untuk Keluarga, Dian Rakyat, Jakarta. 